\title{
ОЦЕНКА ВЛИЯНИЯ ДВУХКОМПОНЕНТНОГО НАБОРА ДЕКОНТАМИНАЦИОННЫХ РАСТВОРОВ «ДКР» НА ГЕНЕТИЧЕСКИЙ МАТЕРИАЛ ВОЗБУДИТЕЛЯ КОРОНАВИРУСНОЙ ИНФЕКЦИИ (SARS-CoV-2)
}

Д.С. Колпаков ${ }^{1}$, И.В. Корниенко ${ }^{1,3,4}$, Т.Г. Фалеева ${ }^{3,5}$, О.Ю. Арамова ${ }^{3,4}$, С.Н. Иванова ${ }^{1}$, И.С. Полищук ${ }^{1}$, М.А. Наумова ${ }^{1}$, Т.И. Твердохлебова ${ }^{1,2}$, А.А. Рындич ${ }^{1}$, Н.В. Алексанина ${ }^{1}$, А.Н. Матузкова ${ }^{1}$, А.Г. Суладзе ${ }^{1}$, Ю.С. Сидоренко ${ }^{3,6}$

${ }^{1}$ ФБУН «Ростовский научно-исследовательский институт микробиологии и паразитологии» Роспотребнадзора, г. Ростов-на-Дону, Российская Федерация

${ }^{2}$ ФГБОУ ВО «Ростовский государственный медицинский университет» Минздрава

России, Ростов-на-Дону, Российская Федерация

${ }^{3}$ ФИЦ «Южный научный центр Российской академии наук», г. Ростов-на-Дону,

Российская Федерация

${ }^{4}$ Южный федеральный университет, Академия биологии и биотехнологии им. Д.И.

Ивановского, г. Ростов-на-Дону, Российская Федерация

${ }^{5}$ ФББУН «Калмыцкий научный центр Российской академии наук», г. Элиста, Российская Федерация

${ }^{6}$ ФГБУ «Национальный медицинский исследовательский центр онкологии» Минздрава России, г. Ростов-на-Дону, Российская Федерация

\section{ESTIMATION OF THE INFLUENCE OF A TWO-COMPONENT SET OF DECONTAMINATION SOLUTIONS "DKR" ON THE GENETIC MATERIAL OF THE CORONAVIRUS INFECTION AGENT (SARS-CoV-2)}

D.S. Kolpakov ${ }^{1}$, I.V. Kornienko ${ }^{1,3,4}$, T.G. Faleeva ${ }^{3,5}$, O. Yu. Aramova ${ }^{3,4}$, S.N. Ivanova ${ }^{1}$, I.S. Polishchuk $^{1}$, M.A. Naumova ${ }^{1}$, T.I. Tverdokhlebova ${ }^{1,2}$, A.A. Ryndich ${ }^{1}$, N.V. Aleksanina ${ }^{1}$, A.N. Matuzkova $^{1}$, A.G. Suladze ${ }^{1}$, Yu.S. Sidorenko ${ }^{3,6}$

${ }^{1}$ FBSI "Rostov Research Institute of Microbiology and Parasitology" Rospotrebnadzor, Rostovon-Don, Russian Federation

${ }^{2}$ FSBEI HE "Rostov State Medical University" of the Ministry of Health of Russia, Rostov-onDon, Russian Federation

${ }^{3}$ FIC "Southern Scientific Center of the Russian Academy of Sciences", Rostov-on-Don, Russian Federation

${ }^{4}$ South Federal University, Academy of Biology and Biotechnology named after V.I. DI. Ivanovsky, Rostov-on-Don, Russian Federation

${ }^{5}$ FGBUN "Kalmyk Scientific Center of the Russian Academy of Sciences", Elista, Russian Federation

${ }^{6}$ FSBI "National Medical Research Center of Oncology" of the Ministry of Health of Russia, Rostov-on-Don, Russian Federation

Резюме. В рамках научно-исследовательской работы проведены испытания двухкомпонентного набора деконтаминационных растворов «ДКР», обозначенных «ДКР1» и «ДКР-2», с целью оценки их влияния на генетический материал возбудителя коронавирусной инфекции (SARS-CoV-2), а также разработки методических подходов в отношении уничтожения возбудителя коронавирусной инфекции (SARS-CoV-2). Экспертное исследование проведено на базе ФБУН «Ростовский научно- 
исследовательский институт микробиологии и паразитологии» Роспотребнадзора и ФИЦ ««Южный научный центр Российской академии наук».

Ключевые слова: COVID-19, SARS-CoV-2, дезинфицирующие средства, двухкомпонентный набор растворов «ДКР», метод ОТ-ПЦР в режиме реального времени

Abstract. As part of the research work, a two-component set of DKR decontamination solutions, designated DKR-1 and DKR-2, were tested in order to assess their effect on the genetic material of the causative agent of coronavirus infection (SARS-CoV-2), as well as development of methodological approaches for the destruction of the causative agent of coronavirus infection (SARS-CoV-2). The expert study was carried out on the basis of the Rostov Research Institute of Microbiology and Parasitology of the Federal Service for Supervision of Consumer Rights Protection and Human Welfare and the Federal Research Center for the Southern Scientific Center of the Russian Academy of Sciences.

Keywords: COVID-19, SARS-CoV-2, disinfectants, two-component set of solutions "DKR", real-time RT-PCR method

Введение. Пандемия COVID-19 вызвала применение небывалых мер предосторожности. Согласно исследованиям распространение вируса от человека к человеку происходит воздушно-капельным путем через вдыхание распыленных в воздухе во время кашля или чихания микрокапель с вирусом, через рукопожатие, при попадании вируса на поверхность предметов с последующим занесением в глаза, нос или рот. В течение нескольких дней SARS-CoV-2 - возбудитель COVID-19 выживает на пластике и нержавеющей стали [1,2]. В связи с чем, необходимо тщательно дезинфицировать поверхности, с которыми чаще всего происходит контакт. Это уменьшит вероятность передачи вируса. Коронавирус выживает благодаря своей оболочке. Разрушив ее, можно легко победить сам вирус. Далеко не каждое средство сможет справиться с вирусом. Для 100\% результата средство должно быть профессиональным и иметь в составе достаточное количество вирулицидных действующих веществ. Для подтверждения эффективности против вирусов такие средства обязаны проходить соответствующие испытания в аккредитованных Роспотребнадзором лабораториях.

Материалы и методы. Для проведения исследования использовали двухкомпонентный набор растворов «ДКР» (прежнее название: «Cell lysis buffer» (сокращенно CLB)): деконтаминационный раствор 1 («ДКР-1») и деконтаминационный раствор 2 («ДКР-2»). Ранее двухкомпонентный набор деконтаминационных растворов «ДКР» прошел успешные испытания по деконтаминационной обработке ДНКсодержащего биологического материала, что отражено в работах [3-8]. Для сравнения проведены испытания следующих коммерческих дезинфицирующих средств:

1. «Асепт Про» производства ООО «Ацея», зарегистрировано в ЕврАзЭС, № KZ.16.01.98.002.Е.000270.04.19 от 05.04.2019 г. (г. Москва);

2. «Pharmsept» (Фармсепт), производства ООО «Уралхимфарм - Плюс», зарегистрировано в России, № RU.77.99.88.002.Е.007106.06.15 от 18.06.2015г. (г. Челябинск);

3. «Фориспот», производства ООО НПК «Альфа», номер госрегистрации № RU.77.99.88.002.Е.003495.08.18 от 14.08.2018 г. (г. Ростов-на-Дону); 
4. Антисептик для рук «Аптеки Дона», производства ГУП РО «Ростовоблфармация» (г. Ростов-на-Дону);

5. «Dr. Arsenin Короносепт», производства ЗАО «Натуротерапия» (г. Ногинск).

Взятие мазков из носоглотки и ротоглотки больных коронавирусной инфекцией осуществляли сухими специальными стерильными зондами (вращательными движениями с поверхности миндалин, небных дужек и задних стенок носоглотки и ротоглотки). Хранение и транспортировку респираторных мазков проводили в реагенте «Транспортная среда для хранения и транспортировки респираторных мазков» (производство ИнтерЛабСервис).

Оценке воздействия деконтаминационных растворов «ДКР» на геном возбудителя SARS-CoV-2 подверглись пробы от 14 больных коронавирусной инфекцией. Оценке воздействия коммерческих дезинфицирующих средств на геном возбудителя SARS-CoV-2 - пробы от 8 больных коронавирусной инфекцией.

Для выделения РНК из биологического материала использовали наборы «РИБОпреп» (производство ИнтерЛабСервис). Выявление PHK коронавируса SARS-CoV-2 проводили методом обратной транскрипции и полимеразной цепной реакции в режиме реального времени с помощью специализированной тест-системы РУ № РЗН 2020/9948 от 01 апреля 2020 года (ДНК-Технология), а также с помощью набора реагентов для выявления PHK коронавируса SARS-CoV-2 методом ОТ-ПЦР в режиме реального времени - РеалБест PHK SARS-CoV-2 (Вектор Бест).

Результаты и обсуждение. Результаты испытаний деконтаминационных растворов «ДКР» по их влиянию на генетический материал (РНК) возбудителя коронавирусной инфекции (SARS-CoV-2) с использованием метода обратной транскрипции и полимеразной цепной реакции в режиме реального времени приведены в таблице 1.

Таблица 1

Результаты обратной транскрипции и полимеразной цепной реакции в режиме реального времени, полученные с помощью специализированной тест-системы РУ № Р3Н 2020/9948

от 01 апреля 2020 года (ДНК-Технология), после 30 мин инкубации мазков из полости носа и ротоглотки больных новой коронавирусной инфекцией с растворами «ДКР».

\begin{tabular}{|l|c|c|c|c|c|c|}
\hline \multicolumn{1}{|c|}{ Обозначение } & $\begin{array}{c}\text { ген } \\
\mathbf{E}\end{array}$ & $\begin{array}{c}\text { delta } \\
\mathbf{C t}\end{array}$ & $\begin{array}{c}\text { ген } \\
\mathbf{N}\end{array}$ & $\begin{array}{c}\text { delta } \\
\mathbf{C t}\end{array}$ & $\begin{array}{c}\text { Общие } \\
\text { коронавирусы }\end{array}$ & $\begin{array}{c}\text { delta } \\
\mathbf{C t}\end{array}$ \\
\hline \multicolumn{1}{|c|}{ Кох } & & $\mathbf{C y 5}$ & & $\mathbf{F A M}$ & \\
\hline контроль 1 & 26,1 & & 25,9 & & 24,7 & \\
\hline контроль 2 & 36,6 & & 38,1 & & 35,8 & \\
\hline контроль 3 & 27,1 & & 25,8 & & 26,4 & \\
\hline контроль 4 & 21,4 & & 20,3 & & 21,3 & \\
\hline контроль 5 & 35,1 & & 34,0 & & 34,1 & \\
\hline контроль 6 & 27,4 & & 26,8 & & 27,3 & \\
\hline растворы «ДКР» эксперимент 1 & & NO & & NO & & NO \\
\hline растворы «ДКР» эксперимент 2 & & NO & & NO & & NO \\
\hline растворы «ДКР» эксперимент 3 & NO & & NO & & NO \\
\hline
\end{tabular}




\begin{tabular}{|l|c|c|c|c|c|c|}
\hline растворы «ДКР» эксперимент 4 & 31 & 9,6 & 29,3 & 9 & 29,8 & 8,5 \\
\hline растворы «ДКР» эксперимент 5 & & NO & & NO & & NO \\
\hline растворы «ДКР» эксперимент 6 & & NO & & NO & & NO \\
\hline
\end{tabular}

Примечания:

1. В контрольные образцы вместо растворов «ДКР» добавляли стерильную деионизированную воду;

2. «эксперимент» - деконтаминационные растворы «ДКР»;

3. «NO»- ПЦР-продукт отсутствует.

Как видно из таблицы 1, инкубация мазков из носоглотки и ротоглотки больных новой коронавирусной инфекцией с деконтаминационными растворами «ДКР» в течение 30 минут приводит к полному уничтожению генома вируса SARS-CoV-2 в 5 из 6 проб. В одном случае (образец 4) инкубация мазков из носоглотки и ротоглотки больных COVID19 с деконтаминационными растворами «ДКР» приводит к снижению концентрации генетического материала вируса в $776\left(2^{9,6}\right)$ раз.

Результаты испытаний деконтаминационных растворов «ДКР» в сравнении с коммерческими дезинфицирующими средствами («Асепт Про», «Pharmsept» (Фармсепт), «Фориспот», Антисептик для рук «Аптеки Дона», «Dr. Arsenin Koроносепт») на генетический материал (РНK) возбудителя коронавирусной инфекции SARS-CoV-2 приведены в таблице 2.

Таблица 2

Результаты обратной транскрипции и полимеразной цепной реакции в режиме реального времени, полученные с помощью специализированной тест-системы РеалБест PHK SARS-

CoV-2 (Вектор Бест), после 30 мин инкубации мазков из полости носа и ротоглотки больных новой коронавирусной инфекцией с деконтаминационными растворами «ДКР», а

также коммерческими дезинфицирующими средствами («Асепт Про», «Pharmsept» (Фармсепт), «Фориспот», Антисептик для рук «Аптеки Дона», «Dr. Arsenin Короносепт»).

\begin{tabular}{|c|c|c|c|}
\hline Образец/обработка & Cp, Rox & delta $\mathrm{Ct}$ & $\begin{array}{c}\text { Показатели } \\
\text { концентрация РНК } \\
\left.\text { вируса (2 }{ }^{\text {delta } \mathrm{Ct}}\right) \\
\text { (во сколько раз } \text { снижается) }\end{array}$ \\
\hline Образец_1_-_контроль (РеалБест PHK SARS-CoV-2) & 20,9 & & \\
\hline Образец_1_-_pаствор_1 (РеалБест PHK SARS-CoV-2) & 25,1 & 4,2 & 18,4 \\
\hline Образец_1_-_раствор_2 (РеалБест PHK SARS-CoV-2) & 27,5 & 6,6 & 97,0 \\
\hline Образец_1_-_раствор_3 (РеалБест PHK SARS-CoV-2) & 28,3 & 7,4 & 168,9 \\
\hline Образец_1_-_pаствор_4 (РеалБест PHK SARS-CoV-2) & 20,6 & $-0,3$ & 0,8 \\
\hline Образец_1_-_раствор_5 (РеалБест PHK SARS-CoV-2) & 26,4 & 5,5 & 45,3 \\
\hline Образец_1_-_paствор_K (РеалБест PHK SARS-CoV-2) & NO & NO & $\begin{array}{l}\text { Полностью } \\
\text { разрушается }\end{array}$ \\
\hline Образец_2_-_контроль (РеалБест PHK SARS-CoV-2) & 18,8 & & \\
\hline Образец_2_-_paствор_1 (РеалБест PHK SARS-CoV-2) & 25,5 & 6,7 & 104,0 \\
\hline Образец_2_-_pаствор_2 (РеалБест PHK SARS-CoV-2) & 29,2 & 10,4 & 1351,2 \\
\hline Образец_2_-_pаствор_3 (РеалБест PHK SARS-CoV-2) & 29,1 & 10,3 & 1260,7 \\
\hline Образец_2_-_pаствор_4 (РеалБест PHK SARS-CoV-2) & 17,6 & $-1,2$ & 0,4 \\
\hline Образец_2_-_pаствор_5 (РеалБест PHK SARS-CoV-2) & 21 & 2,2 & 4,6 \\
\hline Образец_2_-_раствор_K (РеалБест PHK SARS-CoV-2) & 35,7 & 16,9 & 122294,5 \\
\hline Образец_3_-_контроль (РеалБест PHK SARS-CoV-2) & 19,1 & & \\
\hline Образец_3_-_раствор_1 (РеалБест PHK SARS-CoV-2) & 26,3 & 7,2 & 147,0 \\
\hline
\end{tabular}




\begin{tabular}{|c|c|c|c|}
\hline Образец_3_-_раствор_2 (РеалБест PHK SARS-CoV-2) & 29,2 & 10,1 & 1097,5 \\
\hline Образец_3_-_раствор_3 (РеалБест PHK SARS-CoV-2) & 27,4 & 8,3 & 315,2 \\
\hline Образец_3_-_pаствор_4 (РеалБест PHK SARS-CoV-2) & 20,2 & 1,1 & 2,1 \\
\hline Образец_3_-_раствор_5 (РеалБест PHK SARS-CoV-2) & 21,3 & 2,2 & 4,6 \\
\hline Образец_3_-_pаствор_K (РеалБест PHK SARS-CoV-2) & 41,8 & 22,7 & 6813667,0 \\
\hline Образец_4_-_контроль (РеалБест PHK SARS-CoV-2) & 23,4 & & \\
\hline Образец_4_-_раствор_1 (РеалБест PHK SARS-CoV-2) & 28,7 & 5,3 & 39,4 \\
\hline Образец_4_-_раствор_2 (РеалБест PHK SARS-CoV-2) & 31,4 & 8 & 256,0 \\
\hline Образец_4_-_раствор_3 (РеалБест PHK SARS-CoV-2) & 31,4 & 8 & 256,0 \\
\hline Образец_4_-_раствор_4 (РеалБест PHK SARS-CoV-2) & 24,1 & 0,7 & 1,6 \\
\hline Образец_4_-_раствор_5 (РеалБест PHK SARS-CoV-2) & 25,4 & 2 & 4,0 \\
\hline Образец_4_-_pаствор_K (РеалБест PHK SARS-CoV-2) & 24,3 & 0,9 & 1,9 \\
\hline Образец_5_-_контроль (РеалБест PHK SARS-CoV-2) & 18,4 & & \\
\hline Образец_5_-_раствор_1 (РеалБест PHK SARS-CoV-2) & 23,3 & 4,9 & 29,9 \\
\hline Образец_5_-_раствор_2 (РеалБест PHK SARS-CoV-2) & 26,1 & 7,7 & 207,9 \\
\hline Образец_5_-_раствор_3 (РеалБест PHK SARS-CoV-2) & 27,5 & 9,1 & 548,7 \\
\hline Образец_5_-_раствор_4 (РеалБест PHK SARS-CoV-2) & 19,2 & 0,8 & 1,7 \\
\hline Образец_5_-_раствор_5 (РеалБест PHK SARS-CoV-2) & 26,4 & 8 & 256,0 \\
\hline Образец_5_-_раствор_K (РеалБест PHK SARS-CoV-2) & 41,6 & 23,2 & 9635980,2 \\
\hline Образец_6_-_контроль (РеалБест PHK SARS-CoV-2) & 19,7 & & \\
\hline Образец_6_-_раствор_1 (РеалБест PHK SARS-CoV-2) & 23,9 & 4,2 & 18,4 \\
\hline Образец_6_-_раствор_2 (РеалБест PHK SARS-CoV-2) & 26,4 & 6,7 & 104,0 \\
\hline Образец_6_-_раствор_3 (РеалБест PHK SARS-CoV-2) & 27,2 & 7,5 & 181,0 \\
\hline Образец_6_-_раствор_4 (РеалБест PHK SARS-CoV-2) & 20,4 & 0,7 & 1,6 \\
\hline Образец_6_-_раствор_5 (РеалБест PHK SARS-CoV-2) & 24,1 & 4,4 & 21,1 \\
\hline Образец_6_-_pаствор_K (РеалБест PHK SARS-CoV-2) & 22,3 & 2,6 & 6,1 \\
\hline Образец_7_-_контроль (РеалБест PHK SARS-CoV-2) & 18,2 & & \\
\hline Образец_7_-_раствор_1 (РеалБест PHK SARS-CoV-2) & 30,5 & 12,3 & 5042,8 \\
\hline Образец_7_-_раствор_2 (РеалБест PHK SARS-CoV-2) & 24,3 & 6,1 & 68,6 \\
\hline Образец_7_-_раствор_3 (РеалБест PHK SARS-CoV-2) & 30,2 & 12 & 4096,0 \\
\hline Образец_7_-_раствор_4 (РеалБест PHK SARS-CoV-2) & 19,2 & 1 & 2,0 \\
\hline Образец_7_-_раствор_5 (РеалБест PHK SARS-CoV-2) & 30,2 & 12 & 4096,0 \\
\hline Образец_7_-_pаствор_K (РеалБест PHK SARS-CoV-2) & 21,2 & 3 & 8,0 \\
\hline Образец_8_-_контроль (РеалБест PHK SARS-CoV-2) & 18,8 & & \\
\hline Образец_8_-_раствор_1 (РеалБест PHK SARS-CoV-2) & 33 & 14,2 & 18820,3 \\
\hline Образец_8_-_раствор_2 (РеалБест PHK SARS-CoV-2) & 32,2 & 13,4 & 10809,4 \\
\hline Образец_8_-_раствор_3 (РеалБест PHK SARS-CoV-2) & 31,3 & 12,5 & 5792,6 \\
\hline Образец_8_-_раствор_4 (РеалБест PHK SARS-CoV-2) & 19,8 & 1 & 2,0 \\
\hline Образец_8_-_раствор_5 (РеалБест PHK SARS-CoV-2) & 23,3 & 4,5 & 22,6 \\
\hline Образец_8_-_раствор_K (РеалБест PHK SARS-CoV-2) & 39,3 & 20,5 & 1482910,4 \\
\hline
\end{tabular}

Примечания: 1. «раствор_1» - «Асепт Про»;

2. «раствор_2» - «Pharmsept» (Фармсепт);

3. «раствор_3» - «Фориспот»;

4. «раствор_4» - Антисептик для рук «Аптеки Дона»;

5. «раствор_5» - «Dr. Arsenin Короносепт»;

6. «раствор_К» - деконтаминационные растворы «ДКР»;

7. «NO» - ПЦР-продукт отсутствует. 
Вследствие недостаточного перемешивания реакционных смесей в образцах № № 4, 6 и 7 при исследовании воздействия деконтаминационных растворов «ДКР» на геном возбудителя SARS-CoV-2 были проведены повторные испытания для данных объектов. Дополнительно в качестве контроля исследовали коммерческое дезинфицирующее средство «Фориспот».

Результаты повторных сравнительных испытаний деконтаминационных растворов «ДКР», а также коммерческого дезинфицирующего средства «Фориспот» на генетический материал (РНK) возбудителя новой коронавирусной инфекции SARS-CoV-2 приведены в таблице 3.

Таблица 3

Результаты обратной транскрипции и полимеразной цепной реакции в режиме реального времени, полученные с помощью специализированной тест-системы РеалБест PHK SARS-

CoV-2 (Вектор Бест), после 30 мин инкубации мазков из полости носа и ротоглотки больных новой коронавирусной инфекцией с растворами «ДКР», а также коммерческим дезинфицирующим средством «Фориспот».

\begin{tabular}{|c|c|c|c|}
\hline Образец/обработка & $\begin{array}{l}\text { Ct, } \\
\text { Rox }\end{array}$ & $\begin{array}{c}\text { delta } \\
\text { Ct }\end{array}$ & $\begin{array}{c}\text { Показатели концентрация } \\
\text { РНК вируса (2 } 2^{\text {deta Ct })} \\
\text { (во сколько раз снижается) }\end{array}$ \\
\hline Образец_4_контроль (РеалБест PHK SARS-CoV-2) & 22,0 & & \\
\hline Образец_4_раствор_K (РеалБест PHK SARS-CoV-2) & NO & NO & Полностью разрушается \\
\hline Образец_4_раствор_№_3 (РеалБест PHK SARS-CoV-2) & 33,7 & 11,7 & 3327,0 \\
\hline Образец_6_контроль (РеалБест PHK SARS-CoV-2) & 16,8 & & \\
\hline Образец_6_раствор_K_(РеалБест PHK SARS-CoV-2) & 29,0 & 12,2 & 4705,1 \\
\hline Образец_6_раствор_№_3 (РеалБест PHK SARS-CoV-2) & 24,9 & 8,1 & 274,4 \\
\hline Образец_7_контроль (РеалБест PHK SARS-CoV-2) & 14,9 & & \\
\hline Образец_7_раствор_K (РеалБест PHK SARS-CoV-2) & 36,4 & 21,5 & 2965820,8 \\
\hline Образец_7_раствор_№_3 (РеалБест PHK SARS-CoV-2) & 24,3 & 9,4 & 675,6 \\
\hline
\end{tabular}

Полученные данные свидетельствуют о том, что инкубация мазков из носоглотки и ротоглотки больных новой коронавирусной инфекцией с деконтаминационными растворами, обозначенными «ДКР», в течение 30 минут приводит к полному уничтожению генома вируса SARS-CoV-2 в 2 из 8 проб. В 1 из 14 (7,1\%) проб деконтаминационные растворы «ДКР» приводили к снижению концентрации генетического материала вируса SARS-CoV-2 в 776 раз. В остальных 6 из 14 проб (42,9\%) при инкубации мазков из носоглотки и ротоглотки больных коронавирусной инфекцией с деконтаминационными растворами «ДКР» наблюдали значительное снижение концентрации генетического материала вируса: в пробе 2 - в 122294,5 (26,9) раз; в пробе 3

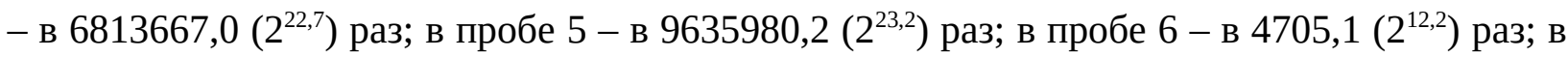
пробе 7 - в 2965820,8 (22,5) раз; в пробе 8 - в 1482910,4 $\left(2^{20,5}\right)$ раз. 
При инкубации мазков из носоглотки и ротоглотки больных коронавирусной инфекцией с коммерческими дезинфицирующими средствами («Асепт Про», «Pharmsept» (Фармсепт), «Фориспот», Антисептик для рук «Аптеки Дона», «Dr. Arsenin Короносепт») в течение 30 минут выявлена меньшая эффективность по сравнению деконтаминационными растворами «ДКР» в отношении деградации генома возбудителя коронавирусной инфекции. Так, ни один из вышеуказанных коммерческих дезинфицирующих средств не приводил к полному уничтожению генома вируса SARSCoV-2.

Таким образом, эффективность коммерческих дезинфицирующих средств в отношении к геному возбудителя SARS-CoV-2 была намного ниже эффективности деконтаминационных растворов «ДКР».

Выводы: В результате проведенных испытаний установлено:

1. Инкубация мазков из носоглотки и ротоглотки больных коронавирусной инфекцией (возбудитель SARS-CoV-2) с деконтаминационными растворами «ДКР» в течение 30 минут приводит к полному уничтожению генома вируса SARS-CoV-2 в 50\% случаев. В 7,1\% проб - к уменьшению концентрации генетического материала вируса SARS-CoV-2 в 776 раз. В 42,9\% проб - к значительному снижению концентрации генетического материала вируса SARS-CoV-2.

2. Инкубация мазков из носоглотки и ротоглотки больных новой коронавирусной инфекцией с коммерческими дезинфицирующими средствами (1. «Асепт Про»; 2. «Pharmsept» (Фармсепт); 3. «Фориспот»; 4. Антисептик для рук «Аптеки Дона»; 5. «Dr. Arsenin Короносепт») в течение 30 минут показала меньшую эффективность по сравнению деконтаминационными растворами «ДКР» в отношении деградации генома возбудителя коронавирусной инфекции. Ни один из вышеуказанных коммерческих дезинфицирующих средств не приводил к полной деградации PHK вируса SARS-CoV-2.

3. Эффективность вышеприведенных коммерческих дезинфицирующих средств в отношении к PHK возбудителя SARS-CoV-2 была намного ниже эффективности изучаемых деконтаминационных растворов «ДКР».

\section{Список литературы}

1. Kampf G., Todt D., Pfaender S., et al. Persistence of coronaviruses on inanimate surfaces and its inactivation with biocidal agents. J Hosp Infect. 2020; 104(3):246-51.

2. Doremalen N., Bushmaker T., Morris D.H., et al.Aerosol and surface stability of HCoV-19 (SARS-CoV-6 2) compared to SARS-CoV-1. DOI: 10.1101/2020.03.09.20033217.

3. Корниенко И.В., Фалеева Т.Г., Шурр Т.Г., Арамова О.Ю., Очир-Горяева М.А., Батиева Е.Ф., Вдовченков Е.В., Мошков Н.Е., Куканова В.В., Иванов И.Н., Сидоренко Ю.С., Татаринова Т.В. Ү-гаплогруппы костных останков из курганных погребений хазарского времени на территории Юга России // Генетика. 2021; 57(4):464-477.

4. Ochir-Goryaeva M.A., Kornienko I.V., Faleeva T.G., Aramova O.Yu., Makhotkin M.A., Kekeev E.A., Burataev E.G., Kukanova V.V., Sidorenko Yu.S., Chartier D.R, Schurr T.G., 
Tatarinova T.V. Bronze Age Rage at Catacomb Culture Burials: A meta-tale of graves, skeletons, and DNA // Journal of Archaeological Science: Reports. 2021. 37. 102894.

5. Корниенко И.В., Панова Т.Д., Фалеева Т.Г., Арамова О.Ю., Сидоренко Ю.С. Молекулярно-генетическая идентификация безымянных захоронений первой половины XVI в. из некрополя Вознесенского собора Московского Кремля // Генетика. 2021. (прошла рецензирование и принята в печать).

6. Корниенко И.В., Фалеева Т.Г., Махоткин М.А., Андриянов А.И., Арамова О.Ю. Инновационный метод выделения древней ДНК // Материалы Международной научной конференции «Азак и мир вокруг него» (Азов, 14-18 октября 2019 г.). С. 268-271.

7. Арамова О.Ю., Фалеева Т.Г., Махоткин М.А., Андриянов А.И., Корниенко И.В. Инновационная методика деконтаминации археологического биологического материала // Материалы VIII научно-практической конференции с международным участием «Генетика - фундаментальная основа инноваций в медицине и селекции» (Ростов-наДону, 26-29 сентября 2019 г.). С. 89-90.

8. Корниенко И.В., Очир-Горяева М.А., Арамова О.Ю., Фалеева Т.Г., Кекеев Э.А., Буратаев Е.Г., Куканова В.В., Сидоренко Ю.С., Татаринова Т.В. Молекулярногенетическое исследование родства скелетов из погребений катакомбной культуры эпохи ранней бронзы курганной группы «Ергенинский» // Материалы X Юбилейной Международной научно-практической конференции «Молекулярная диагностика 2021» (Москва, 09-11 ноября 2021 г.) (принята в печать). 